\title{
A religião nas decisões de controle de CONSTITUCIONALIDADE NO BRASIL: UMA ANÁLISE DAS POSSÍveis CONSEQUÊNCIAS DA PEC 99/11
}

\author{
Igor Suzano MACHADO*
}

RESUMO: Aproveitando o ensejo da proposta de emenda constitucional número 99 de 2011 (PEC 99/11) - que garantiria às associações religiosas maior poder político num cenário de judicialização da política, ao permitir que essas associações proponham ações de controle de constitucionalidade das leis - a presente pesquisa analisa como os argumentos e interesses religiosos têm se feito presentes no Supremo Tribunal Federal brasileiro (STF), independentemente da institucionalização da PEC. Para isso, o estudo recorre à análise de algumas decisões do tribunal sobre ações nas quais a Confederação Nacional os Bispos do Brasil (CNBB), exemplo de associação religiosa que poderia ser favorecida pela PEC, buscou de alguma forma participar. A conclusão a que chega o estudo é que, ainda que por caminhos oblíquos, os argumentos religiosos por vezes se fazem ouvir no controle de constitucionalidade das leis no Brasil, não tendo, contudo, encontrado guarida nas decisões do STF.

PALAVRAS-CHAVE: Controle de Constitucionalidade. Associações religiosas. PEC 99/11. STF.

UFES - Universidade Federal do Espírito Santo. Centro de Ciências Humanas e Naturais. Programa de Pós-graduação em Ciências Sociais. Departamento de Ciências Sociais. Vitória - ES - Brasil. 29075910 - igorsuzano@gmail.com. https://orcid.org/0000-0003-4843-9664. 


\section{Introdução}

Existe um amplo debate acadêmico acerca do tema da chamada judicialização da política ${ }^{1}$ e, ainda que alguns autores questionem esse enquadramento específico, ${ }^{2}$ é difícil negar o protagonismo que o Poder Judiciário e, em especial, que o Supremo Tribunal Federal (STF), tem assumido no Brasil em algumas questões políticas controversas, com seus personagens ocupando lugar de destaque na mídia e suas discussões, que antes eram restritas ao âmbito jurídico, sendo tema do debate público mais amplo. Diante desse cenário, o processo de produção legislativa típica não necessariamente está confinado aos poderes Executivo e Legislativo, pois, após a aprovação das leis em tais instâncias, existe a possibilidade de anulação da lei pelo Judiciário que, assim, torna-se um importante ator de veto na efetivação da vontade política. A presença na arena judiciária, desse modo, passa a ser estrategicamente relevante para atores sociais e políticos que pretendam tornar efetivas suas demandas, tendo em vista que tal efetividade não é mais garantida apenas pelas instâncias legislativas tradicionais.

Ao lado deste problema relativamente novo, persiste um problema bastante antigo: até que ponto poderia a religião e os grupos religiosos influenciarem a política? O encontro desses dois pontos, isto é, a interferência da religião nos rumos de uma política judicializada, desemboca no fato catalisador do debate pretendido por este trabalho: a emergência da Proposta de Emenda Constitucional - PEC 99/11 (BRASIL, 2011a), que visa justamente inserir as associações religiosas no âmbito do controle judicial de constitucionalidade das leis. Proposta pelo deputado evangélico João Campos de Araújo (PSDB-GO), a PEC 99/11 (BRASIL, 2011a) tem como objetivo permitir que as associações religiosas de âmbito nacional possam propor Ações Direta de Inconstitucionalidade (ADI) e Ações Declaratórias de Constitucionalidade (ADECON) junto ao STF. ${ }^{3}$ Esses mecanismos permitiriam às entidades religiosas se manifestarem sobre a inconstitucionalidade ou

\footnotetext{
1 Gostaria de agradecer aos pesquisadores Ana Paula Costa, Bruno Monteiro Duarte e Luciano Rodrigues, estudantes de graduação do curso de Ciências Sociais da Universidade Federal de Viçosa, que contribuíram para a realização da pesquisa que deu origem a este artigo e que, sem eles, não seria possível. Agradeço também à FAPEMIG pelo auxílio prestado na forma de bolsa de Iniciação Científica concedida à pesquisadora Ana Paula Costa.

2 Para uma crítica à ideia de judicialização da política, ver, por exemplo, os trabalhos contidos na coletânea: MOTTA, Luiz Eduardo e MOTA, Maurício. (orgs.) O Estado democrático de direito em questão: teorias críticas da judicialização da política. Rio de Janeiro: Elsevier. 2011

3 Atualmente, o artigo 103 da Constituição preconiza que os legitimados para propor a ADI e a ADECON são o Presidente da República, a Mesa do Senado Federal, a Mesa da Câmara dos Deputados, a Mesa de Assembleia Legislativa ou da Câmara Legislativa do Distrito Federal, o Governador de Estado ou do Distrito Federal, o Procurador-Geral da República, o Conselho Federal da Ordem dos Advogados do Brasil, partido político com representação no Congresso Nacional e confederação sindical ou entidade de classe de âmbito nacional.
} 


\section{A religião nas decisóes de controle de constitucionalidade no Brasil: uma análise das possiveis consequências da PEC 99/11}

constitucionalidade de leis e atos normativos dos poderes Executivo e Legislativo, perante o Judiciário.

$\mathrm{Na}$ justificativa da Emenda Constitucional, encontra-se o argumento da superioridade da Constituição brasileira como delimitadora dos poderes do Estado e o mérito dos Evangélicos como participantes na consolidação de princípios presentes na Constituição e na garantia de liberdade de culto e religião. $O$ texto também aponta o caráter diferenciado com que são tratadas as entidades religiosas, as quais, a partir da Constituição de 1988 (BRASIL, 2017), passaram a gozar de uma autonomia privada com intervenção mínima do Poder Público, diferenciando as associações religiosas das associações e organizações de classes e de fundações e associações sem fins lucrativos. Segundo a justificativa,

O movimento evangélico cresce no Brasil, portanto, associado ao sentimento de liberdade cívica que vem à luz com a República, onde a Constituição como norma fundamental assume grande significado político, tornando-se, sobretudo, instrumento de garantia individual e de limitação do poder do Estado, e como tal, passa a iluminar o sistema jurídico nacional. Neste contexto, não há como não se reconhecer o mérito dos Evangélicos brasileiros em coadjuvar na consolidação de princípios no cerne da Constituição, como garantidores da liberdade de culto e de religião. [...] Com este paradigma, considerando que os agentes estatais no exercício de suas funções públicas, muitas vezes se arvoram em legislar ou expedir normas sobre assuntos que interferem direta ou indiretamente no sistema de liberdade religiosa ou de culto nucleado na Constituição, faz-se necessário garantir a todas as Associações Religiosas de caráter nacional o direito subjetivo de promoverem ações para o controle de constitucionalidade de leis ou atos normativos, na defesa racional e tolerante dos direitos primordiais conferidos a todos os cidadãos indistintamente e coletivamente aos membros de um determinado segmento religioso, observados o caráter nacional de sua estrutura. (BRASIL, 2011a, p. 3-4).

Ou seja, a problemática de fundo que embasa a presente pesquisa provém de um tema clássico da filosofia política: a relação tendencialmente conflituosa entre a política e a religião. ${ }^{4}$ Contudo, tal tema ganha relevância e novos contornos no Brasil contemporâneo. Relevância devido a uma série de questões políticas importantes que atualmente desafiam dogmas das religiões majoritárias do país, como o reconhecimento de relações homoafetivas, avanços científicos que atuam diretamente sobre a constituição humana e possibilidades de reconhecimento do

\footnotetext{
4 Para citar apenas dois exemplos, contudo bastante eloquentes devido ao seu impacto na teoria política, podemos pensar na busca de uma fundamentação não religiosa para o poder político no Leviatã, de Thomas Hobbes, e o clamor pela tolerância religiosa em Cartas sobre a tolerância, de John Locke.
} 
direito feminino ao aborto. E novos contornos devido ao atual contexto de potencial judicialização da política, em que tais questões políticas importantes são decididas não apenas na arena legislativa, mas, por vezes, também na arena judiciária, em que não impera, necessariamente, a lógica majoritária. Em meio a esse contexto, emerge a PEC 99/11 (BRASIL, 2011a), que garantiria às associações religiosas maior poder político nesse cenário judicializado, ao poderem propor ações de controle de constitucionalidade.

Segundo Christina Vital e Paulo Lopes (2003), pode-se observar, ao longo da história do Brasil, uma relação próxima do Estado e da igreja Católica. Isso é verificado desde a colonização, com as missões de padres que detinham uma parceria com o Estado, e até ações e medidas que cabiam ao Estado brasileiro, como a concessão de licença para construir igrejas. No Império, a religião católica ainda era a oficial, e somente na República, em 1989, surgem traços de laicidade, com a separação entre o poder político e as instituições religiosas. ${ }^{5}$ Durante toda a história, o modelo Católico serviu de parâmetro para dizer o que era ou não religioso no país. Na segunda metade do século XX, contudo, há o surgimento e crescimento dos evangélicos no Brasil, iniciando uma ameaça ao sistema Católico. O questionamento do status quo operado pelo crescimento desses atores no cenário político, social, econômico e cultural teria sido fundamental para consolidar o pluralismo religioso, assim como para questionar as intensas relações entre o catolicismo e o Estado brasileiro.

Conforme salienta Maria Lucia Montes (2012),

o crescimento dos evangélicos, que lhes deu visibilidade pública, se refletiu também no interior do próprio grupo, que desde a década de 80 procura, e agressivamente, marcar sua presença na cena pública, valendo-se da participação política. O grupo que se tornaria conhecido como a "bancada evangélica" do Congresso Nacional Constituinte, representou um primeiro exemplo, inédito, dessa participação, no interior de um grupo que historicamente se mostrara avesso à política. (MONTES, 2012, p.32).

Christina Vital e Paulo Lopes (2003) falam de um segredo público - isto é, algo amplamente conhecido, mas que não é explicitado - ao se referirem à relação histórica mantida entre Igreja Católica e o Estado brasileiro. Assim, eles complementam, com a revelação desse segredo público, outras religiões buscaram

5 Dados os limites de espaço do artigo, o processo de laicização - ou de secularização, variante anglófona geralmente associada a um fenômeno social mais amplo que não se resume à separação entre igreja e Estado - não será abordado diretamente enquanto tema de estudo, sendo tomado como pressuposto, apesar do reconhecimento das tensões que não permitem tratá-lo como um fenômeno homogêneo, seja em termos de desenvolvimento histórico, seja em termos de disseminação social. Nesse sentido ver: TAYLOR, Charles. Uma Era Secular. São Leopoldo-RS: Editora Unisinos, 2010. 


\section{A religião nas decisóes de controle de constitucionalidade no Brasil: uma análise das possiveis consequências da PEC 99/11}

estreitar e legitimar suas relações com o Estado. Com isso, a defesa da igualdade de tratamento do Estado quanto às várias religiões implicaria a defesa das congregações religiosas como mais um grupo de pressão político-social que tem o direito de desfrutar do mesmo espaço que diversos grupos seculares. Logo, a religião seria mais uma das correntes de pensamento a oferecer um discurso, disputando com a ciência uma visão da verdade. Assim, diversas religiões, incluindo a própria religião Católica, não mais presumida como partícipe do governo, vêm buscando reconhecimento e igualdade de direitos de acesso aos bens políticos. Com a via do judiciário se abrindo enquanto importante fonte de acesso a tais bens políticos, não é de surpreender que as religiões queiram se fazer presentes também nessa via. É neste contexto que emerge a PEC 99/11 (BRASIL 2011a), catalisadora da discussão que embasa a presente pesquisa.

Tal pesquisa irá se valer de um estudo empírico sobre um conjunto de ações de controle de constitucionalidade julgadas pelo STF, nas quais um exemplo de associação religiosa que seria beneficiada pela PEC, a Confederação Nacional dos Bispos do Brasil (CNBB), mostrou-se interessada. ${ }^{6}$ Com base na análise dessas ações, acreditamos ser possível não apenas lançar luz sobre como associações religiosas têm participado e influenciado o controle de constitucionalidade das leis no Brasil sob o ordenamento jurídico atual, como também conjecturar a respeito de como as religiões poderiam vir a participar desse controle de constitucionalidade no caso de aprovação da PEC.

\section{Judicialização da política, mobilização do direito e escolha dos casos estudados}

Desde o trabalho pioneiro de C. Neal Tate e Torbjörn Vallinder (1995), a expressão judicialização da política tornou-se parte do vocabulário de estudos sobre a relação entre a política e a justiça, inclusive no Brasil. Conforme destaca Ran Hirschl (2008, p. 119-123), a expressão tornou-se uma espécie de termo "guardachuva", para representar uma miríade de situações distintas. Ela se debruça, segundo o autor, especialmente sobre três processos inter-relacionados. Primeiramente, no nível mais abstrato, refere-se à disseminação do discurso, jargão, regras e processos jurídicos na esfera política e na formulação de políticas públicas - que muitos

\footnotetext{
6 É bom ressaltar que a escolha da CNBB se justifica pela sua representatividade da mais numerosa religião no Brasil, que é um país majoritariamente católico. Mesmo assim, há de se destacar que, caso a associação religiosa escolhida fosse outra, por exemplo, de matriz evangélica, tal como o deputado proponente da PEC 99/11, os resultados poderiam ser diferentes, tendo em vista as posições não uniformes de católicos e de diferentes vertentes protestantes em temas morais controversos, conforme fica claro no estudo empreendido por Naara Luna (2013).
} 
preferem se referir em termos de "juridificação". Em segundo lugar, num nível mais concreto, diz respeito à extensão da província de atuação dos juízes na formulação de políticas públicas e organização da burocracia e órgãos políticos, inclusive mediante atuação na defesa de direitos e garantias individuais, de forma a restringir a atuação dos poderes Executivo e Legislativo. Por fim, há ainda casos de judicialização da "megapolítica", em que juízes chegam a definir questões relativas à segurança nacional, planejamento econômico, processo eleitoral, etc.

Tentando evitar certo viés de cima para baixo contido nos estudos sobre a judicialização, que dedicariam demasiada atenção à ação especificamente dos juízes e tribunais, há autores, no Brasil (MACIEL, 2011; LOSEKANN, 2013) e fora do país, que apostam na noção de mobilização do direito, em substituição à de judicialização da política. Tal noção visaria prestar mais atenção às demandas da sociedade civil, sob um ponto de vista, digamos, "de baixo para cima", seja focando os litigantes individuais, seja em frutífero diálogo com a literatura sobre movimentos sociais em demandas coletivas (MCCANN, 2008, p. 523).

Em consonância com os estudos sobre a mobilização do direito, a presente pesquisa se interessa pelo caminho de baixo para cima do controle de constitucionalidade das leis, exercido pela sociedade civil organizada. Mais especificamente, por associações religiosas, de que é um exemplo famoso no país a CNBB. Contudo, ela recorre a um expediente de análise típico dos estudos que focam a judicialização da política, que é se concentrar nas decisões do Judiciário, nesse caso, nos votos dos ministros do STF, tendo entre seus objetivos conhecer a resposta institucional a tais demandas. Com base na análise de tais decisões, a nosso ver, seria possível não apenas compreender a interação atual entre as associações religiosas e o STF, como também conjecturar o impacto que a mudança legislativa pretendida pela PEC 99/11 (BRASIL, 2011a) poderia trazer ao contexto político nacional.

Tendo isso em vista, serão analisados os posicionamentos do STF nas seguintes decisões:

- Julgamento da Ação Direta de Inconstitucionalidade (ADI) 3510 (BRASIL, 2008), responsável por debater a possibilidade de utilização de embriões resultantes de fertilização in vitro para pesquisas com células-tronco;

- Julgamento da Arguição de Descumprimento de Preceito Fundamental (ADPF) 54 (BRASIL, 2012), responsável por debater a possibilidade de interrupção de gestação de feto anencefálico; e

- Julgamento conjunto da ADPF 132 (BRASIL, 2011b) e da ADI 4.277 (BRASIL, 2011c), responsável por debater a possibilidade de reconhecimento jurídico de uniões homoafetivas. 


\section{A religiäo nas decisóes de controle de constitucionalidade no Brasil: uma análise das possiveis consequências da PEC 99/11}

Tais decisões representam quatro resultados encontrados na busca de jurisprudência do STF, via página eletrônica do tribunal, pela sigla CNBB, já apontada anteriormente como um caso exemplar de associação religiosa que se beneficiaria da instituição da PEC 99/11 (BRASIL, 2011a). Outros resultados foram descartados por apresentarem ou ações que não foram conhecidas pelo tribunal ou ações que, à época de realização da pesquisa, não contavam com decisão final. ${ }^{7}$ Ainda que se refiram a casos pontuais, acreditamos que tais ações forneçam estudos de caso importantes para a compreensão da presença atual de associações religiosas no STF e permitem a reflexão acerca dos possíveis efeitos da efetivação da emenda constitucional que garantiria às associações religiosas participação direta no controle de constitucionalidade. Tendo em vista que ainda não contamos com exemplos de tal participação direta, teríamos, ao menos, a possibilidade de análise de decisões que se inserem em exemplos de tentativas de participação indireta de uma associação religiosa específica em julgamentos de temas que, a seu ver, diziam-lhe respeito. Debates morais correlatos, pode-se imaginar, num contexto de efetivação da PEC 99/11 (BRASIL, 2011a), provavelmente levariam as associações religiosas a mobilizarem o direito na tentativa de defesa de seus interesses e visões de mundo. Ou seja: mesmo que não esgotem o tema, os casos estudados permitiriam a reflexão sobre ele com base em alguns de seus aspectos centrais por tratarem de casos paradigmáticos que funcionam como metáforas de toda uma categoria presumida importante (GLYNOS; HOWARTH, 2007).

\section{Primeiro caso analisado: a ADI 3510 e a controvérsia a respeito das pesquisas com células-tronco embrionárias}

Em 2008, o Supremo Tribunal Federal brasileiro foi provocado a avaliar a constitucionalidade da recém-aprovada Lei de Biossegurança - lei 11.105/05 - que permitia, para fins de pesquisa e terapia, a utilização de células-tronco originadas de embriões humanos produzidos por fertilização in vitro. Ainda que a lei previsse restrições para as pesquisas, permitindo o uso apenas de embriões que seriam descartados no processo de fertilização, sob o consentimento dos progenitores, o $\operatorname{artigo~} 5^{\circ}$ da referida lei provocou polêmica. Seus opositores argumentavam que o embrião é portador de vida e, portanto, precisaria ter sua integridade resguardada contra a retirada de suas células-tronco - procedimento que causaria a destruição do embrião como um todo.

\footnotetext{
7 Um caso constitucional importante e que contou com a participação ativa da CNBB cuja decisão final, todavia, foi posterior à data de coleta de dados da pesquisa, foi a ação de controle de constitucionalidade sobre a obrigatoriedade de ensino religioso nas escolas.
} 
O então Procurador Geral da República, Cláudio Lemos Fonteles, alegou a inconstitucionalidade do art. $5^{\circ}$ da lei sob o argumento de que seu texto afrontava preceitos constitucionais, ofendendo a inviolabilidade do direito à vida. Com base nessa premissa, em 30 de maio de 2005, o Procurador Geral da República propôs a ADI 3.510 (BRASIL, 2008), que foi finalmente julgada pelo STF em 2008. A ação contou com os votos do Ministros Carlos Ayres Britto (relator), Cesar Peluso, Celso de Mello, Gilmar Mendes, Ellen Gracie, Eros Grau, Menezes Direito, Cármem Lúcia, Ricardo Lewandowski, Joaquim Barbosa e Marco Aurélio Mello.

O Ministro Carlos Ayres Britto, relator da ação, em seu voto, sustentou seu argumento com base em preceitos constitucionais relacionados ao direito à saúde, de maneira que a Lei de Biossegurança, sob esse ponto de vista, segundo ele, não desprezaria o embrião in vitro, mas traria esperança a pessoas que sofrem com doenças sem cura. Durante a votação, foram trazidos à tona princípios como 0 da paternidade responsável e da autonomia da vontade, defesa do direito à saúde, e tutela da vida, de forma que com seis votos contra cinco, a ação foi julgada inteiramente improcedente e não houve alteração da lei.

Apesar da maioria dos Ministros ter acompanhado o voto do relator, cinco deles - Menezes Direito, Ricardo Lewandowski, Eros Grau, César Peluso e Gilmar Mendes - propuseram alterações à lei. A ADI 3510 (BRASIL, 2008) contou ainda com cinco amici curiae ${ }^{8}$ - Conectas Direitos Humanos, Centro de Direitos Humanos, Movimento em prol da vida, Instituto de bioética, Direitos humanos e gênero, além da CNBB - e também com uma audiência pública, na qual representantes da comunidade científica, professores e pesquisadores da área puderam se manifestar. A audiência pública foi realizada em abril de 2007 e, em maio de 2008, a ADI 3510 (BRASIL, 2008) foi julgada improcedente.

Ao fazermos uma análise dos argumentos presentes nos votos, percebemos que os ministros não viam a lei como inconstitucional, ainda que alguns deles tenham proposto alterações que restringissem as pesquisas com células tronco embrionárias, como forma de adequar o texto da lei e os ditames constitucionais. As Ministras Ellen Gracie e Cármen Lúcia fizeram ponderações sobre o benefício que as pesquisas com células tronco embrionárias trariam para a vida das pessoas que sofrem com doenças e traumas sem cura. $\mathrm{O}$ argumento de ambas segue o voto do relator, defendendo que se o destino final dos embriões é o descarte, não há violação do direito à vida ao promover as pesquisas.

\footnotetext{
8 Plural de Amicus Curiae, ou "Amigo da Corte" que, no glossário do STF, significa: Intervenção assistencial em processos de controle de constitucionalidade por parte de entidades que tenham representatividade adequada para se manifestar nos autos sobre questão de direito pertinente à controvérsia constitucional. Não são partes dos processos; atuam apenas como interessados na causa. Disponível em: http://www.stf.jus.br/portal/glossario/verVerbete.asp?letra=A\&id=533 Acesso em 3/6/2015. Acessado em: 03 jun. 2015.
} 


\section{A religiäo nas decisóes de controle de constitucionalidade no Brasil: uma análise das possiveis consequências da PEC 99/11}

O Ministro Joaquim Barbosa, por sua vez, defendeu que o ordenamento jurídico do Brasil apresenta escalas de tutela à vida, como os direitos do nascituro e o da criança e do adolescente, e isto depende do seu estágio de desenvolvimento, de modo que não existiria similaridade na proteção do Estado aos nascituros e aos que já nasceram. O Ministro Marco Aurélio também compactuou com este argumento e acrescentou que a personalidade jurídica é adquirida somente por meio do nascimento com vida, o que não é o caso dos embriões, já que estes não serão implantados no útero materno, única circunstância que poderia lhes conferir a possibilidade de desenvolvimento e nascimento com vida.

Já o ministro Lewandowski afirmou que "as pesquisas com embriões humanos congelados são admitidas desde que não sejam destruídos nem tenham o seu potencial de desenvolvimento comprometido". O potencial referido seria a finalidade do embrião, isto é, a vida, sendo que e esta, segundo o seu argumento, deve ser preservada. É isso que embasa em seu voto, assim como no voto do ministro Gilmar Mendes, o clamor por uma "sentença de perfil aditivo", responsável por acrescentar à lei em questão novos requisitos capazes de proteger os embriões, por exemplo, de práticas eugênicas. Ou seja, tais pesquisas exigiriam um controle mais amplo por parte das autoridades do que o previsto em lei, já que podem criar problemas de manipulação genética e de venda clandestina de embriões.

Um dos votos mais críticos à da Lei de Biossegurança foi o do reconhecidamente católico Ministro Menezes Direito, ${ }^{9}$ que questionou os resultados concretos das pesquisas com células tronco embrionárias. As pesquisas com células tronco presentes no embrião, para Menezes Direito, até o momento não teriam apresentado resultados concretos, sendo apenas hipóteses sobre possíveis soluções para doenças até agora sem cura, como lesões na medula óssea. Em contrapartida, segundo ele, existiriam pesquisas com células tronco adultas e estas já apresentariam resultados positivos para a cura de algumas doenças. Desse modo, para o Ministro, deveria existir uma reflexão cuidadosa sobre as pesquisas com células tronco embrionárias, uma vez que poderia haver outras alternativas mais viáveis e menos polêmicas, já que, sob sua visão, o embrião é vida humana desde o encontro do material genético masculino e feminino e precisa, por isso, ter sua vida protegida pelo ordenamento jurídico. Mesmo assim, Menezes Direito destaca que o seu julgamento não busca decidir entre um olhar científico ou religioso a respeito das pesquisas, mas sim consubstanciar um olhar jurídico, desprendido tanto de concepções dogmáticas, quanto de argumentos científicos.

9 Fato amplamente noticiado na época de sua morte, como na matéria Perda no judiciário: morre o ministro do Supremo Menezes Direito de Débora Pinho e Aline Pinheiro (2009). 


\section{Segundo caso analisado: a ADPF 54 e a polêmica em torno da interrupção da gravidez de fetos anencefálicos}

A ADPF 54 (BRASIL, 2012), movida pela Confederação Nacional dos Trabalhadores na Saúde (CNTS) objetivava declarar inconstitucional o entendimento de que a interrupção da gravidez de feto anencefálico seria espécie aborto, e, consequentemente, identificável como crime nos termos do Código Penal vigente. O resultado do julgamento da ADPF 54 (BRASIL, 2012) caminhou no sentido de explicitar que, por uma interpretação do Código Penal em conformidade com a Constituição (BRASIL, 2017), a conduta do profissional de saúde que interrompesse a gravidez de feto anencefálico não deveria ser criminalizada. Nesse sentido votaram, além do relator Marco Aurélio Mello, os ministros Joaquim Barbosa, Celso de Mello, Rosa Weber, Luiz Fux, Cármen Lúcia e Ayres Britto.

Ao longo do julgamento, além da CNBB, a organização não governamental feminista Católicas pelo Direito de Decidir, a Associação Nacional Pró-vida e Prófamília e a Associação do Desenvolvimento da Família pleitearam o ingresso no feito como amicus curiae, o que, no entanto, foi indeferido. Ainda assim, o relator ouviu em audiência pública tais entidades e outras afins, de modo a esclarecer o tema posto em julgamento. Contudo, não deixou de frisar, em seu voto, o caráter laico do Estado brasileiro, destacando que "a questão posta nesse processo [...] não pode ser examinada sob os influxos de orientações morais religiosas".

Dois ministros se manifestaram pela improcedência da ação: Ricardo Lewandowski e o ex-seminarista Cezar Peluso. ${ }^{10} \mathrm{O}$ Ministro Ricardo Lewandovski votou pela improcedência da ação, argumentando que não caberia ao Poder Judiciário o papel de solucionador de todos os problemas sociais, jurídicos, filosóficos, etc. Segundo ele, o silêncio do legislador do Código Penal de 1940 teria sido proposital ao não afastar a punibilidade da interrupção da gestação de um feto malformado, complementando que, "caso desejasse, o Congresso Nacional já teria alterado a legislação criminal vigente para incluir o aborto eugênico dentre as hipóteses de interrupção da gravidez isenta de punição". Ainda segundo o ministro, “o Supremo Tribunal Federal só pode exercer o papel de legislador negativo, cabendo-lhe somente retirar do ordenamento jurídico as normas incompatíveis com a Constituição Federal. A função de criar normas", ele completa, "é do Congresso Nacional, dos representantes eleitos pelo voto". No mais, o Ministro destaca que "isentar de pena o aborto de fetos com anencefalia poderia abrir portas para a mesma medida nos casos de embriões portadores de outras doenças, genéticas ou

\footnotetext{
${ }^{10}$ A informação consta da participação do ex-ministro na pesquisa História Oral do Supremo, realizada pela Escola de Direito da FGV-Rio. A entrevista concedida por César Peluso, pode ser conferida em: FONTAINHA, Fernando de Castro; SILVA, Angela Moreira Domingues da; ALMEIDA, Fábio Ferraz de. História oral do Supremo [1988-2013] (2015).
} 


\section{A religião nas decisóes de controle de constitucionalidade no Brasil: uma análise das possiveis consequências da PEC 99/11}

adquiridas que, de algum modo, levem ao encurtamento da vida”. Já o ministro Cézar Peluso entendeu incabível desconsiderar como crime o aborto de feto anencefálico, sob o risco de se ter o "feto, reduzido, no fim das contas, à condição de lixo ou de outra coisa imprestável e incômoda" para a qual "não é dispensada, de nenhum ângulo, a menor consideração ética ou jurídica, nem reconhecido grau algum da dignidade jurídica e ética que lhe vem da incontestável ascendência e natureza humanas"

Dentre os votos favoráveis à descriminalização da interrupção de gravidez de fetos anencefálicos, o voto do Ministro Gilmar Mendes mostrou-se o mais significativo no que se refere à atuação das entidades religiosas, ainda que ouvidas apenas em audiência pública e não admitidas como amici curiae. Para o Ministro, o debate envolvido na ação, "era ético e moral, e despertou a manifestação de diversas organizações da sociedade, inclusive as religiosas". Com isso, tal debate teria tornado claro que "a laicidade do Estado não impede que organizações religiosas possam participar e se manifestar nos debates público, até mesmo porque seus argumentos também se relacionam a razões públicas e não somente a razões religiosas". Gilmar Mendes destacou ainda que "a participação de diferentes grupos em processos judiciais de grande significado para toda a sociedade cumpre uma função de integração extremamente relevante no Estado de Direito". Isto é, "ao ter acesso a essa pluralidade de visões, o STF passa a contar com os benefícios decorrentes dos subsídios técnicos, implicações político-jurídicas e elementos de repercussão econômica que possam vir a ser apresentados pelos 'amigos da corte"'. Por tal motivo, completa, não seria "razoável a ausência, nesse julgamento, de entidades da sociedade como a CNBB e ONGs".

\section{Terceiro caso analisado: a união homoafetiva no julgamento conjunto da ADPF 132 e da ADI 4277}

Um dos temas que pautaram o STF e mobilizaram a sociedade brasileira no ano de 2011 foi o tema da ADPF 132 (BRASIL, 2011b) e da ADI 4.277 (BRASIL, 2011c). Ambas tinham como meta a equiparação da união estável entre pessoas do mesmo sexo à entidade familiar preconizada pelo artigo 1.723 do Código Civil, segundo o qual: "é reconhecida como entidade familiar a união estável entre o homem e a mulher, configurada na convivência pública, contínua e duradoura e estabelecida com o objetivo de constituição de família". Nesse sentido, o direito brasileiro passaria a reconhecer como entidade familiar também a união entre pessoas do mesmo sexo, de natureza pública, contínua e duradoura, formada com o objetivo de constituição de família. A ADPF 132 (BRASIL, 2011b) e a ADI 4.277 (BRASIL, 2011c) foram impetradas pelo Governador do Estado do Rio de Janeiro, 
e pela Procuradoria Geral da República, respectivamente. As duas foram apreciadas em conjunto, em julgamento cujo relator fora o Ministro Ayres Britto.

Para o relator Ayres Britto, se a união homoafetiva não era proibida pela legislação, automaticamente passaria a ser permitida. Sendo permitida, ela geraria os mesmos direitos que outras uniões estáveis. O Ministro foi enfático na argumentação de que todas as pessoas da espécie humana são iguais, sendo descabíveis distinções de qualquer natureza. Para o relator, os cidadãos são "iguais para suportar deveres, ônus e obrigações de caráter jurídico positivo, iguais para titularizar direitos, bônus e interesses também juridicamente positivados". Seguindo o relator, todos os ministros da corte votaram a favor da procedência da ação.

O ministro Luiz Fux acrescentou em seu voto que a homossexualidade não é crença, e nem opção de vida. E sustentou a tese de que se a homossexualidade não é crime, não há porque se impedir a constituição de uma família homoafetiva. Alegou ainda que a não equiparação violaria direitos fundamentais inerentes à personalidade dos indivíduos que vivem sob orientação sexual minoritária. Assinalou também que a questão transcendia os limites territoriais do Rio de Janeiro, e que se deveria atribuir eficácia erga omnes ${ }^{11}$ à decisão, já que, realizando-se sobre lei nacional, o julgamento teria de ter também alcance igualmente nacional. Cármen Lúcia, a terceira ministra do tribunal a votar, acompanhou o relator em sua totalidade, defendendo a tese de que a escolha por uma união homoafetiva é individual e única, não podendo ser limitada pelo Direito. Seguindo a mesma linha de pensamento, o Ministro Joaquim Barbosa defendeu que o fundamento constitucional para o reconhecimento das uniões homoafetivas não se encontra no artigo 226, parágrafo $3^{\circ}$ da Constituição Federal (BRASIL, 2017), local explicitamente destinado a regular as uniões estáveis entre homem e mulher, mas em todos os dispositivos do texto magno que protegem os direitos fundamentais. E afirmou que a Constituição prima pela proteção dos direitos fundamentais e veda todo tipo de discriminação. Também seguindo o voto do relator, Marco Aurélio de Mello acrescentou que o Estado existe para auxiliar os projetos de vida dos indivíduos, e mesmo que o Brasil seja um país laico, o fundamentalismo religioso ainda influencia no avanço da questão da homoafetividade, em especial na tramitação dos projetos no legislativo, postura que nada mais é, na visão do Ministro, do que a materialização do preconceito. No voto seguinte, o ministro Celso de Mello endossa tal entendimento, afirmando que não se deve confundir questões jurídicas com questões de caráter moral ou religioso, já que o Brasil é um país laico. Último a manifestar a sua posição frente a matéria, o à época presidente do STF Ministro Cezar Peluso fora também favorável à ação. Na

\footnotetext{
11 A referência a uma eficácia erga omnes faz alusão ao fato de o resultado da ação afetar a todos os brasileiros, e não apenas aqueles envolvidos na ação. No exemplo em pauta, ainda que tenha sido o governador do Rio de Janeiro entrou com a ação, o resultado não valeria apenas para os moradores do Rio de Janeiro, mas para toda a população brasileira.
}

112 Estud. sociol. Araraquara v.23 n.45 p.101-121 jul.-dez. 2018 


\section{A religiäo nas decisóes de controle de constitucionalidade no Brasil: uma análise das possiveis consequências da PEC 99/11}

visão dele, o Congresso Nacional tem a responsabilidade de legislar sobre o tema: "Há uma convocação que a corte faz para o poder Legislativo para que assuma essa tarefa a que não se sentiu muito propenso a exercer: regulando essa equiparação".

Vale ressaltar que os ministros Ricardo Lewandowski e Gilmar Mendes votaram a favor das ações, porém fizeram ressalvas em relação ao julgamento. Ricardo Lewandowski, ao proferir a sua decisão, trilhou um caminho pelo conceito de família, trazido pelas Constituições brasileiras anteriores. Mostrou-se contrário ao texto dos votos dos outros ministros, pois, para ele, não seria concebível a classificação da união homoafetiva como união estável, tendo em vista o explícito texto constitucional, representante da efetiva vontade do legislador. Na defesa do seu voto, Lewandowski traz o conceito de "integração analógica", que é a ideia de se aplicar a essa nova decisão a legislação mais próxima, até que ela seja definitivamente regulada por lei aprovada no Congresso. Logo, para o ministro, a união homoafetiva deveria ser entendida como um quarto tipo de família, diferente da relação de casamento, união estável ou família monoparental. Como consequência, por analogia - e apenas por analogia - Ricardo Lewandowski, estendeu os direitos referentes à união estável dos heterossexuais às unidades familiares formadas por homossexuais. Outro membro da suprema corte que se colocou resistente ao julgamento foi o ministro Gilmar Mendes. Ainda que favorável ao reconhecimento jurídico da união homoafetiva, o ministro se mostrou preocupado e fez ressalvas, preferindo, por exemplo, não se pronunciar sobre a adoção por casais homoafetivos.

Além dos votos dos ministros, uma característica importante do julgamento foi o ingresso de um número expressivo de amici curiae, em sua maioria favoráveis à procedência das duas ações. Além de doze entidades representantes de homossexuais, a CNBB e a Associação Eduardo Banks se fizeram presentes, apresentando-se como as vozes contrárias à procedência da ação. $\mathrm{O}$ relator aceitou o pedido de um número tão grande de amici curiae argumentando que essa presença era necessária em razão da complexidade do tema e da sua grande relevância.

\section{A análise das decisões}

O que se pode concluir a respeito das decisões analisadas e da relação entre religião e direito, na atual democracia constitucional brasileira? Primeiramente, pode-se concluir que nosso controle de constitucionalidade é potencialmente aberto à interferência de grupos religiosos, que são convidados, ainda que na qualidade de informantes e não partes da ação, a se manifestarem sobre a melhor interpretação dos princípios constantes na Constituição. Mesmo assim, tal presença, nas ações analisadas, não conseguiu redundar em aceitação das demandas desses grupos religiosos nas decisões do tribunal. 
Na ADI 3510 (BRASIL, 2008), o relator utilizou de várias áreas do conhecimento para construir seu argumento, inclusive o olhar da religião. Mas os votos contrários às pesquisas não mencionaram Deus, nem uma religião específica, fundamentando seus argumentos na ciência. A assumidamente católica Ministra Cármen Lúcia, ${ }^{12}$ inclusive, declarou em seu voto que: "o Brasil é minha religião" e a "Constituição é minha Bíblia". Igualmente, no que tange à ADPF 54 (BRASIL, 2012), viu-se que o papel das entidades religiosas foi apenas o de levar alguma informação aos autos por meio de audiência pública, mas que não tiveram como efeito influenciar diretamente a decisão dos ministros, que, em sua totalidade, mais uma vez ressaltaram a importância e necessidade do julgamento com base na lei. Por fim, no julgamento conjunto da ADPF 132 (BRASIL, 2011b) e ADI 4277 (BRASIL, 2011c), a religião se mostrou para alguns ministros como possível entrave ao entendimento propriamente jurídico, mas não deixou de marcar presença com a CNBB entre os amici curiae presentes ao julgamento.

Um primeiro ponto a ser observado, portanto, é que, caso a PEC 99/11 (BRASIL, 2011a) seja aprovada, é possível que ela não traga alterações profundas para o controle de constitucionalidade das leis no país. Isso porque os grupos religiosos podem acionar os agentes de controle de constitucionalidade atuais, como o Procurador Geral da República (caso da ADI 3510), ou os partidos políticos de laços mais intensos com grupos religiosos, para requerer de forma indireta a retificação de uma lei que as desagrade, assim como podem mobilizar argumentos próprios participando da ação como amicus curiae ou como participantes de audiências públicas sobre os temas em julgamento. O efeito prático talvez fosse o de encurtar o caminho para tais entidades proporem as ações, já que, ao invés de dependerem das bancadas religiosas ou do Procurador Geral da República, poderiam ajuizá-las diretamente.

Logo, em uma análise inicial, com uma possível aprovação da PEC 99/11 (BRASIL, 2011a), não haveria uma grande transformação do cenário de controle de constitucionalidade brasileiro, uma vez que os grupos religiosos, de alguma forma, rodeiam o STF, seja como amici curiae, seja participando de audiências públicas, seja pela via de outros agentes que possuem o direito constitucional de controle de constitucionalidade. Isto é, grupos religiosos - ao menos católicos - têm voz dentro do STF. Porém, tal voz precisa se adequar a uma linguagem que não é exatamente a da confissão religiosa, mas a do direito secular. E, ainda assim, não se trata de voz que ecoa explicitamente nas razões que fundamentam as decisões dos nossos ministros, ao menos explicitamente.

\footnotetext{
12 Informação veiculada em matérias publicadas na época de sua posse como presidente do Supremo, como por exemplo: FREITAS, Vladimir Passos de. Ministra Carmen Lúcia conduzirá bem o Poder Judiciário do Brasil (2016).
} 


\section{A religião nas decisóes de controle de constitucionalidade no Brasil: uma análise das possiveis consequências da PEC 99/11}

Afinal, ainda que a religião apareça, os valores religiosos dos ministros não são explicitados em seus votos, assim como os amici cuariae, mesmo de vinculação religiosa explícita, como a CNBB, buscam contornar o uso de argumentos estritamente religiosos. ${ }^{13} \mathrm{E}$, apesar de se observar alguma sobreposição entre as demandas das entidades religiosas na função de amici curiae ou durante as audiências públicas e os votos de alguns ministros assumidamente católicos, esta sobreposição não é perfeita, como mostram os votos da ministra Carmen Lúcia.

Essa análise, contudo, se baseia em forte aderência às verbalizações dos envolvidos e pode resultar em um problema que assombra as pesquisas tributárias da técnica de análise de discurso: apenas dar voz, de forma irrefletida, ao grupo pesquisado. Por isso, autores como Jason Glynos e David Howarth (2007), chamam atenção para como se evitar os riscos de a análise de discurso apenas confirmar o discurso analisado, perdendo, inclusive, capacidade crítica. É o risco de uma perspectiva que, nas palavras dos autores, apenas produz uma auto-interpretação contextualizada. Dessa forma, se a religião não aparece explicitamente na justificação pública dos envolvidos no controle de constitucionalidade, ainda assim é possível questionar a sua importância para a motivação privada dos mesmos. Conforme destaca Naara Luna (2013), em estudo sobre a ADI 3510 e a ADPF 46:

No contexto pesquisado, o comportamento de ocultação do vínculo confessional ou de afirmar o caráter científico de suas colocações denota a restrição ao discurso religioso como emissor de verdades em um Estado laico por um lado. Por outro lado, a argumentação religiosa se traveste de científica ou jurídica, mas não deixa de existir no núcleo de valores que fundamenta o debate (LUNA, 2013, p. 90).

Claro que a motivação privada de agentes sociais se trata de informação de difícil aferição, pois tal motivação não é totalmente transparente sequer para os próprios atores sociais. Contudo, é possível fazer algumas inferências com base nos dados coletados, tomando como referência uma orientação metodológica contida em Logics of Critical Explanation in Social and Political Theory, de Glynos e Howarth (2007). Nessa obra, eles propõem, como dimensão da análise crítica de discurso, destacar a "lógica fantasmática", isto é, calcada na fantasia, por trás de algumas construções discursivas. Isso é possível ressaltando articulações obscuras e problemáticas nos discursos dos agentes sociais, que são obscurecidas justamente por que não seriam aceitas na justificação pública. Segundo os autores:

\footnotetext{
${ }^{13}$ No caso das uniões homoafetivas, por exemplo, a CNBB alegou que a Constituição Federal não prevê este tipo de união. Segundo ela, a Constituição Federal estabelece limitação expressa, ao prever união estável entre homem e mulher, e não entre seres do mesmo sexo. Portanto, de acordo com o advogado da CNBB, não se trata de uma lacuna constitucional, de forma que não caberia ao Judiciário, mas sim ao Legislativo, se for o caso, alterar o correspondente dispositivo constitucional, aduzindo ainda que aquele discurso "deve ser centrado na Constituição, e não em questões filosóficas ou metafísicas".
} 
[A] evidência empírica indicativa da presença de um objeto fantasmático pode ser identificada perguntando-se se ela resiste ou não à divulgação pública oficial. Além disso, nós podemos dizer que aspectos da realidade social que lidam com gozo fantasmaticamente estruturado sempre possuem características contraditórias, exibindo posições incompatíveis [tradução nossa]. (GLYNOS; HOWARTH, p.148).

Tomando como parâmetro essa orientação metodológica, podemos encontrar no argumento religioso uma possível motivação privada que garante a continuidade de um discurso jurídico, ainda que, do ponto de vista da teoria jurídica, ele se mostre incoerente. Vejamos o caso no Ministro Levandowski nas três ações analisadas. Enquanto sua posição na ADI 3510 (BRASIL, 2008) foi no sentido de cobrar do STF uma postura ativa, editando uma sentença de perfil aditivo que somasse à Lei de Biossegurança algumas exigências que restringissem a pesquisa com célulastronco, nas demais decisões sua postura foi no sentido de dar à corte um papel autocontido, privilegiando a produção legislativa feita nos demais poderes. Não obstante a possibilidade de uma mudança genuína de orientação teórica por parte do ministro, não é infundada a hipótese de que, diante de casos que contrariavam dogmas cristãos, como o reconhecimento do aborto de feto anencefálico e a união homoafetiva, Lewandowski tenha visto a necessidade de recuo do Judiciário para não se chocar com suas próprias preferências religiosas, enquanto que, quando a lei atacada já era o ponto de conflito perante os valores cristãos - caso da Lei de Biossegurança - o ministro viu para o Judiciário, pelo contrário, a necessidade de adoção de competências legislativas como única forma de defesa dos valores religiosos em risco. Isto é, nas posturas aparentemente contraditórias do ministro, não haveria fidelidade a uma matriz teórica jurídica, mas haveria adesão aos valores de uma determinada religião. ${ }^{14}$

Este último ponto é importante, pois as conclusões do estudo, de que a PEC 99/11 (BRASIL, 2011a) provavelmente teria pouco impacto no controle de constitucionalidade das leis brasileiras, está levando em conta o conjunto de ministros responsáveis pelo julgamento das ações analisadas. Uma mudança desses quadros poderia acarretar também uma mudança nesse contexto. Da mesma forma, ainda que precisando ser traduzida numa linguagem laica, a motivação religiosa, que provavelmente se faz presente na atuação do ex-Procurador Geral da República e do ministro Lewandowski, pode se tornar mais frequente em novos procuradores e ministros, de forma que, se hoje os argumentos religiosos rondam a casa o STF sem serem convidados a se sentar na sala principal, num outro contexto, em que asso-

\footnotetext{
${ }^{14}$ Provavelmente da religião Católica, ainda que, ao contrário de outros ministros, não tenhamos encontrado informações confiáveis sobre a filiação religiosa do ministro Lewandowski.
} 


\section{A religiäo nas decisöes de controle de constitucionalidade no Brasil: uma análise das possiveis consequências da PEC 99/11}

ciações religiosas possam propor ações de controle de constitucionalidade e novos ministros sejam mais receptivos aos seus argumentos, tal quadro pode vir a se alterar.

Ou seja, na tumultuosa relação entre religião, política e direito, no Brasil, parece menos impactante uma mudança legislativa como a patrocinada pela PEC 99/11 (BRASIL, 2011a) do que uma mudança nos quadros do STF, com ministros mais dispostos a aceitarem os argumentos religiosos na formatação de uma razão pública a pautar a leitura das nossas normas constitucionais. Na última indicação ao STF, inclusive, foi real a possibilidade de nomeação de um novo ministro cuja fé religiosa parece ser bastante influente sobre sua visão sobre o direito, ${ }^{15}$ e que conta com apoio explícito da CNBB e seguimentos evangélicos. ${ }^{16}$ Dessa forma, trata-se de uma disputa em aberto, com batalhas realizadas em dois fronts diferentes: na seara legislativa, com a luta pela aprovação da PEC, e nas nomeações dos ministros da corte, buscando nomes dispostos a congregarem religião e justiça.

\section{Considerações finais}

Quando se reuniram em Paris para discutir alguns dos principais temas concernentes à atuação do Judiciário nas democracias contemporâneas, Robert Badinter, Stephen Breyer, Ronald Dworkin, Dieter Grim, Antonio Cassese e Gil Carlos Rodriguez incluíram na pauta de discussão a atuação das cortes como o que eles chamaram de pontificado laico (secular papacy) (BADINTER; BREYER, 2004). Tal tópico visava cobrir o fenômeno, que lhes chamara atenção, das cortes constitucionais estarem, em alguns casos, substituindo as religiões como instância última de decisão de questões morais controversas. Tal fenômeno, relevante sob qualquer contexto democrático, adquire importância ainda maior no Brasil, uma democracia recente, na qual, além de as cortes decidirem questões morais controversas, temos que as associações religiosas mostraram interesse em participar ativamente do controle judicial de constitucionalidade das leis por meio da PEC 99/11 (BRASIL, 2011a).

Quando observamos as decisões do STF nas quais uma associação religiosa específica - a CNBB - tentou influir, o que se observa é que o controle de constitucionalidade brasileiro se abre à possibilidade da participação das associações religiosas como grupo interessado na defesa dos princípios contidos na Constituição. Contudo, na disputa pela interpretação dos princípios constitucionais, as associações

\footnotetext{
${ }_{15}$ Nesse sentido ver: Cotado para o STF defende que mulher obedeça ao marido de Mario Cesar Carvalho (2017).

${ }_{16}$ Nesse sentido ver: Em carta a Temer, presidente da CNBB sugere indicação de Ives Gandra Filho para o STF (PAINEL, 2017). Assim como, Guilherme Amado em Ives Gandra Filho recebe apoio de pastores evangélicos (2017).
} 
religiosas e os ministros que não deixam de assumir alguma confissão de fé aceitam que a laicidade do Estado exige que os argumentos apresentados na esfera pública sejam, pelo menos, filtrados pela linguagem estritamente jurídica ou científica.

Isso não quer dizer que valores religiosos não desempenhem, ainda que de forma indireta, influência sobre as decisões. Ainda que isso varie muito de ministro para ministro, é possível identificar a defesa de algumas pautas que guardam afinidades com demandas do catolicismo, em ministros reconhecidos por seus laços de formação com o cristianismo. O caso do ministro Lewandowski parece exemplar nesse sentido, apesar de inferências poderem ser feitas também a respeito dos exministros Menezes Direito e Cézar Peluso.

Diante desse quadro, a aprovação da PEC 99/11 (BRASIL, 2011a) teria seu impacto em grande parte condicionado pela recepção das demandas das associações religiosas pelos ministros do STF, o que, por sua vez, seria dependente da configuração da corte quanto aos seus ministros. Se, na atual conjuntura, isso provavelmente minimiza os impactos da alteração constitucional, as coisas podem mudar a depender dos futuros ministros indicados ao tribunal.

\section{RELIGION IN THE BRAZILIAN JUDICIAL REVIEW DECISIONS: AN ANALYSIS OF THE POSSIBLE CONSEQUENCES OF 'PEC 99/11'}

ABSTRACT: Taking into account the proposal of constitutional amendment number 99, year 2011 (PEC 99/11) - which gives greater political power to religious associations in the context of increased judicialization of politics by allowing these associations to introduce legislation for judicial review - this research examines how religious arguments and interests have gained ground in the Brazilian Supreme Court (STF), even without the institutionalization of the PEC. In order to do this, the article analyzes decisions of the court in cases that the National Confederation of Brazilian Bishops Brazilian (CNBB) - an example of a religious association that would benefit from the PEC - has shown interest. The conclusion reached by the study is that, although through indirect means, religious arguments are sometimes heard in Brazilian judicial reviews. However, these arguments have not found shelter in our supreme court's decisions.

KEYWORDS: Judicial review. Religious associations. PEC 99/11. STF. 
A religiäo nas decisóes de controle de constitucionalidade no Brasil: uma análise das possiveis consequências da PEC 99/11

\title{
LA RELIGIÓN EN LAS DECISIONES DE CONTROL DE CONSTITUCIONALIDAD EN BRASIL: UN ANÁLISIS DE LAS posibles consecuencias de la PEC 99/11
}

\begin{abstract}
RESUMEN: Aprovechando la ocasión de la propuesta de enmienda constitucional número 99 de 2011 (PEC 99/11) - que garantizaría a las asociaciones religiosas mayor poder político en un escenario de judicialización de la política, al permitir que esas asociaciones propongan acciones de control de constitucionalidad de las leyes - esta investigación analiza cómo los argumentos e intereses religiosos se han hecho presentes en el Supremo Tribunal Federal brasileño (STF), independientemente de la institucionalización de la PEC. Para eso, el estudio recurre al análisis de algunas decisiones del tribunal sobre acciones en las que la Confederación Nacional de los Obispos de Brasil (CNBB), ejemplo de asociación religiosa que podría ser favorecida por la PEC, buscó de alguna forma participar. La conclusión a la que llega el estudio es que, aunque por caminos oblicuos, los argumentos religiosos a veces se hacen oír en el control de constitucionalidad de las leyes en Brasil, no pudiendo sin embargo, encontrar guarida en las decisiones del STF.
\end{abstract}

PALABRAS CLAVE: Control de Constitucionalidad. Asociaciones religiosas. PEC 99/11. STF.

\section{REFERÊNCIAS}

AMADO, Guilherme. Ives Gandra Filho recebe apoio de pastores evangélicos. O Globo, 01 de fevereiro de 2017. Disponível em: <http://blogs.oglobo.globo.com/lauro-jardim/post/ ives-gandra-filho-recebe-apoio-de-pastores-evangelicos.html>. Acessado em: 02 fev. 2017.

BADINTER, Robert.; BREYER, Stephen. (Orgs.) Judges in Contemporary Democracy. New York/London: New York University Press. 2004.

BRASIL. Supremo Tribunal Federal-STF. AÇÃO DIRETA DE INCONSTITUCIONALIDADE 3510 DISTRITO FEDERAL. Brasília, 29 de maio de 2008. Disponível em: <http:// redir.stf.jus.br/paginadorpub/paginador.jsp?docTP $=\mathrm{AC} \&$ docID $=611723>$. Acessado em 03 dez. 2018.

BRASIL. Câmara dos Deputados. PROPOSTA DE EMENDA À CONSTITUIÇÃO (PEC) No 99, DE 2011. Brasília, 2011a. Disponível em: <http://www.camara.gov.br/proposicoes Web/fichadetramitacao?idProposicao=524259>. Acessado em: 03 dez. 2018. 
BRASIL. Supremo Tribunal Federal-STF. ARGUIÇÃO DE DESCUMPRIMENTO DE PRECEITO FUNDAMENTAL 132 RIO DE JANEIRO. Brasília, 05 de maio de 2011b. Disponível em: $<$ http://redir.stf.jus.br/paginadorpub/paginador.jsp?docTP=AC\&docID=628633>. Acessado em 03 dez. 2018.

BRASIL. Supremo Tribunal Federal-STF. AÇÃO DIRETA DE INCONSTITUCIONALIDADE 4.277 DISTRITO FEDERAL. Brasília, 05 de maio de 2011c. Disponível em: $<$ http:// redir.stf.jus.br/paginadorpub/paginador.jsp?docTP $=\mathrm{AC} \&$ docID $=628635>$. Acessado em: 03 dez. 2018.

BRASIL. Supremo Tribunal Federal-STF. ARGUIÇÃO DE DESCUMPRIMENTO DE PRECEITO FUNDAMENTAL 54 DISTRITO FEDERAL. Brasília, 12 de abril de 2012. Disponível em: $<$ http://www.stf.jus.br/portal/processo/verProcessoPeca.asp?id=13638 9880\&tipoApp=.pdf $>$. Acessado em: 03 dez. 2018.

BRASIL. Constituição da República Federativa do Brasil de 1988. Tribunal Regional do Trabalho da $2^{\text {a }}$ Região. Atualizada até a EC no 99, de 14/12/2017. Diário Oficial da União - DOU, 15 de dezembro de 2017. Disponível em: <http://www.trtsp.jus.br/legislacao/ constituicao-federal-emendas >. Acessado em: 30 nov. 2018.

CARVALHO, Mario Cesar. Cotado para o STF defende que mulher obedeça ao marido. FOLHA DE SÃO PAULO, 25 de janeiro de 2017. Disponível em: < http://www1.folha.uol. com.br/poder/2017/01/1852822-cotado-para-o-stf-defende-que-mulher-obedeca-ao-marido. shtml>. Acessado em: 02 de fev. 2017.

FONTAINHA, Fernando de Castro; SILVA, Angela Moreira Domingues da; ALMEIDA, Fábio Ferraz. História oral do Supremo [1988-2013] - Cezar Peluso. Fundação Getúlio Vargas - FGV-Rio, 2015, volume 4. Disponível em: <http:/historiaoraldosupremo.fgv.br/ sites/historiaoraldosupremo.fgv.br/files/entrevistados/arquivos/volume_4_-_cezar_peluso. pdf $>$. Acessado em: 02 fev. 2017.

FREITAS, Vladimir Passos de. Ministra Carmen Lúcia conduzirá bem o Poder Judiciário do Brasil. Consultor Jurídico - Conjur, 14 de agosto de 2016. Disponível em: <http://www. conjur.com.br/2016-ago-14/segunda-leitura-ministra-carmen-lucia-conduzira-bem-poderjudiciario-brasil>. Acessado em: 02 fev. 2017.

GLYNOS, Jason.; HOWARTH, David. Logics of critical explanation in social and political theory. London: Routledge, 2007.

HIRSCHL, Ran. The judicialization of politics. In: WHTTINGTON, Keith E.; KELEMEN, Daniel R.; CALDEIRA, Gregory A. (ed.) Oxford Handbook of Law and politics. Oxford: Oxford University Press, 2008.

HOBBES, Thomas de Malmesbury. Leviatã. Tradução de João Paulo Monteiro e Maria Beatriz Nizza da Silva. São Paulo: Editora Nova Cultural, 1999. (Coleção Os Pensadores). 


\section{A religião nas decisóes de controle de constitucionalidade no Brasil:}

uma análise das possiveis consequências da PEC 99/11

LOCKE, John. Cartas sobre a tolerância. Tradução de Anoar Aiex. São Paulo: Abril Cultural, 1991. (Coleção Os Pensadores).

LOSEKANN, Cristiana. Mobilização do direito como repertório de ação coletiva e crítica institucional no campo ambiental brasileiro. Dados, Rio de Janeiro, vol. 56, n. 2, P. 311349, 2013.

LUNA, Naara. O direito à vida no contexto do aborto e da pesquisa com células-tronco embrionárias: disputas de agentes e valores religiosos em um Estado laico. Revista Religião e Sociedade, Rio de Janeiro, vol. 33, n. 1, p. 71-97, 2013.

MACIEL, Débora Alves. Ação Coletiva, mobilização do direito e instituições políticas: o caso da Campanha da Lei Maria da Penha. Revista Brasileira de Ciências Sociais, São Paulo, vol. 26, n. 77, P. 97-111, 2011.

MCCANN, Michael. Litigation and legal mobilization. In: WHTTINGTON, Keith E.; KELEMEN, Daniel R.; CALDEIRA, Gregory A. (ed.) Oxford Handbook of Law and politics. Oxford: Oxford University Press, 2008.

MOTTA, Luiz Eduardo.; MOTA, Maurício. (org.) O Estado democrático de direito em questão: teorias críticas da judicialização da política. Rio de Janeiro: Elsevier. 2011.

MONTES, Maria Lúcia. As figuras do sagrado: entre o público e o privado na religiosidade brasileira. São Paulo: Companhia das Letras, 2012.

PAINEL. Em carta a Temer, presidente da CNBB sugere indicação de Ives Gandra Filho para o STF. FOLHA DE SÃO PAULO, 01 de fevereiro de 2017. Disponível em: $<\mathrm{http}: / /$ painel. blogfolha.uol.com.br/2017/02/01/em-carta-a-temer-presidente-da-cnbb-sugere-indicacaode-ives-gandra-filho-para-o-stf/>. Acessado em: 02 fev. 2017.

PINHO, Débora; PINHEIRO, Aline. Perda no judiciário: morre o ministro do Supremo Menezes Direito. Consulto Jurídico - Conjur, 01 de setembro de 2009. Disponível em: $<$ http://www.conjur.com.br/2009-set-01/morre-ministro-supremo-carlos-alberto-menezesdireito>. Acessado em: 02 fev. 2017.

TATE, C. Neal. e VALLINDER, Torbjörn. (eds) The global expansion of Judicial Power. New York/London: New York University Press, 1995.

TAYLOR, Charles. Uma Era Secular. São Leopoldo, RS: Editora Unisinos, 2010.

VITAL, Cristina.; LOPES, Paulo Victor Leite. Religião e Política: Uma análise da atuação de parlamentares evangélicos sobre direito das mulheres e de LGBTs no Brasil. Rio de Janeiro: Fundação Heinrich Boll \& Instituto de estudos da religião (ISER), 2003.

Recebido em 17/08/2018.

Aprovado em 14/10/2018. 
